\title{
Minor Omphalocele, Type IV Ileal Atresia, Congenital Ostomy
}

\author{
Barlas Etensel', Ali Onur Erdem¹, Özge Çoşkun', İbrahim Meteoğlu², \\ Münevver Kaynak Türkmen³ ${ }^{3}$ Mustafa Harun Gürsoy ${ }^{1}$ \\ ${ }^{1}$ Department of Pediatric Surgery, Adnan Menderes University, Aydin, Turkey \\ ${ }^{2}$ Department of Pathology, Adnan Menderes University, Aydin, Turkey \\ ${ }^{3}$ Department of Neonatology, Adnan Menderes University, Aydin, Turkey \\ Email: betensel@gmail.com
}

Received 10 June 2014; revised 5 July 2014; accepted 2 August 2014

Copyright (C) 2014 by authors and Scientific Research Publishing Inc.

This work is licensed under the Creative Commons Attribution International License (CC BY). http://creativecommons.org/licenses/by/4.0/

(c) (i) Open Access

\begin{abstract}
Abstract: Omphalocele is often associated with the presence of other congenital anomalies. Isolated minor omphaloceles are known to have a favorable prognosis. Case reports have demonstrated nonclassical associations occurring in minor omphaloceles. Intestinal atresia is seldom described as being associated with minor omphaloceles. Special attention should be paid to intestinal exploration in small omphaloceles to avoid complications. Here we report a new association of a minor omphalocele, type IV ileal atresia and congenital ostomy.
\end{abstract}

\section{Keywords}

Minor Omphalocele, Type IV Ileal Atresia, Congenital Ostomy

\section{Introduction}

Omphalocele is a congenital midline abdominal wall defect that results in herniation of intraabdominal contents covered by a lining of peritoneum and amnion. Its incidence is 1 per 5000 live births. Major omphalocele have $50 \%$ to $70 \%$ of other major congenital anomalies such as Beckwith-Wiedemann syndrome, pentalogy of Cantrell, and vertebral, anal, cardiac, trachea, esophagus, renal, and limb anomalies. Isolated minor omphaloceles are known to have a favorable prognosis. Some case reports have demonstrated nonclassical associations occurring in minor omphaloceles [1]-[5]. Intestinal atresia is seldom described as being associated with minor omphaloceles. Here we report a new case of a minor omphalocele with association of very rare anomalies.

\section{Case Report}

A 26-year-old multiparous woman was admitted to our delivery room at 35 weeks of gestation. She had no pre-

How to cite this paper: Etensel, B., Erdem, A.O., Çoşkun, Ö., Meteoğlu, İ., Türkmen, M.K. and Gürsoy, M.H. (2014) Minor Omphalocele, Type IV Ileal Atresia, Congenital Ostomy. Open Journal of Pediatrics, 4, 177-179.

http://dx.doi.org/10.4236/ojped.2014.43024 
natal sonography (US) and follow-up. A premature girl was delivered weighing 2120 gr. The Apgar scores were 9 and 10 at 1 and 5 minutes, respectively. Findings during her neonatal physical examination were consistent with a minor omphalocele (22 mm diameter) and a mature intestinal stoma opening like an ostomy on the right side of the sac (Figure 1). There were no other gross congenital anomalies and she had no abdominal distention. In NICU, bilious intestinal discharge was observed from the stoma. Hemogram and biochemistry was normal. Abdominal ultrasonography and echocardiography were normal.

Operation was performed following a search for other associated malformations. Radiopaque material was given from stoma and C-arm flouroscopy showed that it fills the intestines. Laparotomy revealed ileal loops in the sac and an end ileostomy located on the right side of minor omphalocele. Two cm distal to this end ileostomy, there were severe adhesions between the intestines and the sac. Adhesiolysis could not be performed. There wasn't any adhesion in the abdominal cavity. Unused ileum and colon were detected. Distal unused ileum was opened and controlled. Two type I atretic segments of ileum (type IV ileal atresia) located 11 and $14 \mathrm{~cm}$ distal to the adhesions were observed (Figure 2). This required a resection of the ileum including ostomy, adhesions and type IV atresia and anastomosis together with the primary closure of the abdominal wall defect. Postoperative course was uneventful.

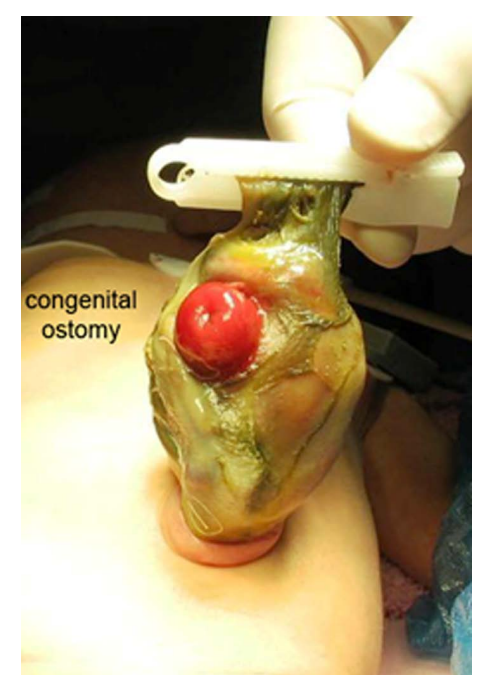

Figure 1. Minor omphalocele.

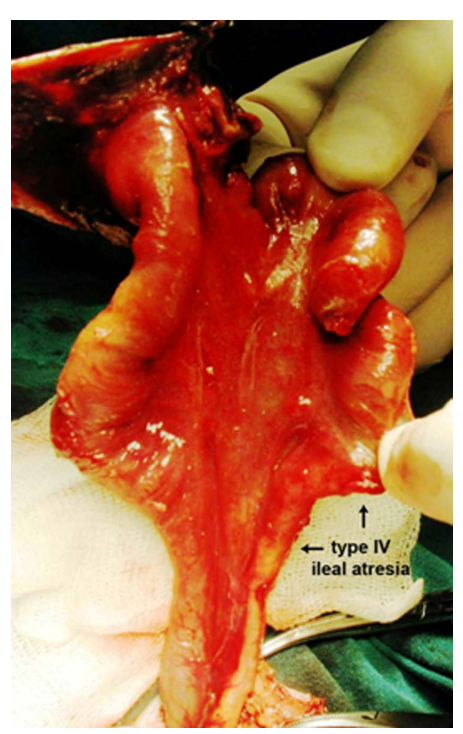

Figure 2. Intestinal adhesions and type IV ileal atresia. 


\section{Discussion}

Omphalocele consists of a herniation of the intraabdominal viscera through an open umbilical ring, which fails to close during embryogenesis. During week 6 of gestation, the midgut undergoes a physiologic herniation through the umbilicus at which time counterclockwise rotation around the superior mesenteric artery and intestinal elongation occurs. By 10 to 12 weeks, the midgut undergoes reduction into the abdominal cavity where it assumes normal anatomical position. Omphalocele represents a disturbance in this process, although the exact mechanism by which this occurs is not known.

Diagnosis of omphalocele can be established during the prenatal period through ultrasound examination in the majority of cases. Omphalocele is often associated with the presence of other major congenital anomalies. These associated anomalies imply a potential identical, etiologic process as they are often midline defects. If the omphalocele is isolated, the prognosis depends mainly on the size of the hernia. Isolated minor omphaloceles are known to have a favorable prognosis [1]-[5].

Intestinal atresia is described seldom as being associated with minor omphalocele, especially type IV atresia is very rare. Salomon [5] reported an ileal atresia in a case report and Wakhlu [6] reported only one ileal atresia in a serie of 45 cases with minor omphaloceles. Type IV ileal atresia (two type I atresia) was a part of our case. Animal experiments and clinical scenarios have clearly described the etiopathogenesis of intestinal atresias. Intrauterine mesenteric vascular accidents due to volvulus, intussusception, internal hernia, and constriction of the mesentery in a tight gastroschisis or omphalocele defect have been observed. However, type I atresia differs from other intestinal atresia. Type I intestinal atresia results from incomplete embryonic recanalization of intestines [7]. In fetuses with congenital intestinal atresia, the proximal bowel typically appears as distended loops with peristaltic movement. Perforation of ileum is more frequent because its wall is less compliant in comparison with jejunum [7].

In our case, the narrow ring of the minor omphaloceles might cause a closed-loop intestinal obstruction. That could be another cause of intestinal perforation and formation of a congenital mature stoma on the sac. This stoma worked as an end ileostomy in the fetal and postnatal period. In NICU, bilious intestinal discharge was observed from the stoma.

The minor omphaloceles are more than just simple "hernias of the cord" and are associated with their own distinct variety of anomalies when compared to larger omphaloceles. The current approaches used to screen for associated anomalies may miss the intestinal anomalies present within minor omphaloceles. The pediatrician and pediatric surgeon must then be cognizant of the potential for undetected intestinal anomalies to be present at the time of surgical correction [1]-[5]. Special attention should be paid to intestinal exploration, looking for an associated gastrointestinal abnormality, even if the abdominal wall defect is small. Through this careful exploration, serious complications can be avoided.

No report has been described in the literature of association between minor omphaloceles, type IV ileal atresia and congenital ostomy. Our case highlights the occurrence of this very rare combination of congenital malformation.

\section{References}

[1] Kumar, H.R., Jester A.L. and Ladd, A.P. (2008) Impact of Omphalocele Size on Associated Conditions. Journal of Pediatric Surgery, 43, 2216-2219. http://dx.doi.org/10.1016/j.jpedsurg.2008.08.050

[2] Haas, J., Achiron, R., Barzilay, E., Yinon, Y., Bilik, R. and Gilboa, Y. (2011) Umbilical Cord Hernias: Prenatal Diagnosis and Natural History. Journal of Ultrasound Medicine, 30, 1629-1632.

[3] Pal, K., Ashri, H. and Wabari, A.A. (2009) Congenital Hernia of the Cord. Indian Journal of Pediatrics, 76, 319-321. http://dx.doi.org/10.1007/s12098-009-0061-x

[4] Ferede, A., Tareen, F. and Gillick, J. (2009) Omphalocele Minor Associated with Complete Absence of the Large Bowel. Pediatric Surgery International, 25, 651-653. http://dx.doi.org/10.1007/s00383-009-2397-8

[5] Salomon, L.J., Benachi, A., Auber, F., Bonnard, A., Nihoul-Fékété, C. and Dumez, Y. (2002) Omphalocele: Beyond the Size Issue. Journal of Pediatric Surgery, 37, 1504-1505. http://dx.doi.org/10.1053/jpsu.2002.35433

[6] Wakhlu, A. and Wakhlu, A. K. (2000) The Management of Exomphalos. Journal of Pediatric Surgery, 35, 73-76. http://dx.doi.org/10.1016/S0022-3468(00)80017-2

[7] Lee, J.H., Im, S.A. and Lee, G. (2011) Evolution of Sonographic Findings in a Fetus with Ileal Atresia. Journal of Clinical Ultrasound, 39, 359-362. http://dx.doi.org/10.1002/jcu.20824 
Scientific Research Publishing (SCIRP) is one of the largest Open Access journal publishers. It is currently publishing more than 200 open access, online, peer-reviewed journals covering a wide range of academic disciplines. SCIRP serves the worldwide academic communities and contributes to the progress and application of science with its publication.

Other selected journals from SCIRP are listed as below. Submit your manuscript to us via either submit@scirp.org or Online Submission Portal.
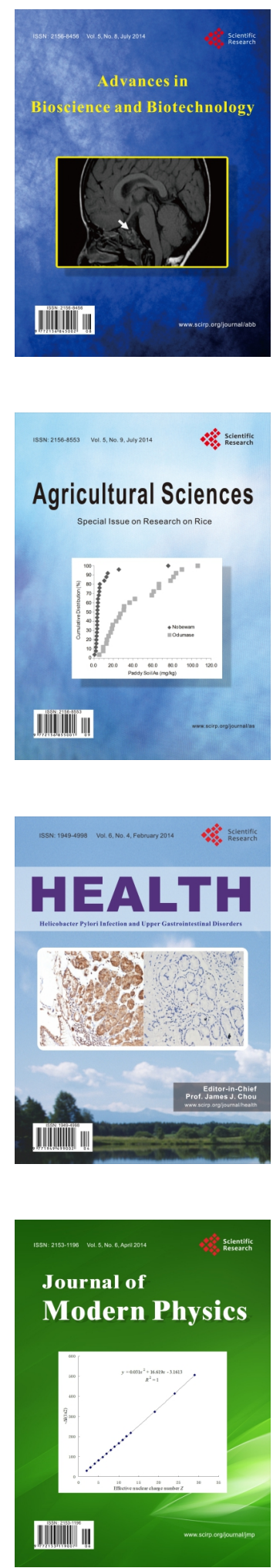
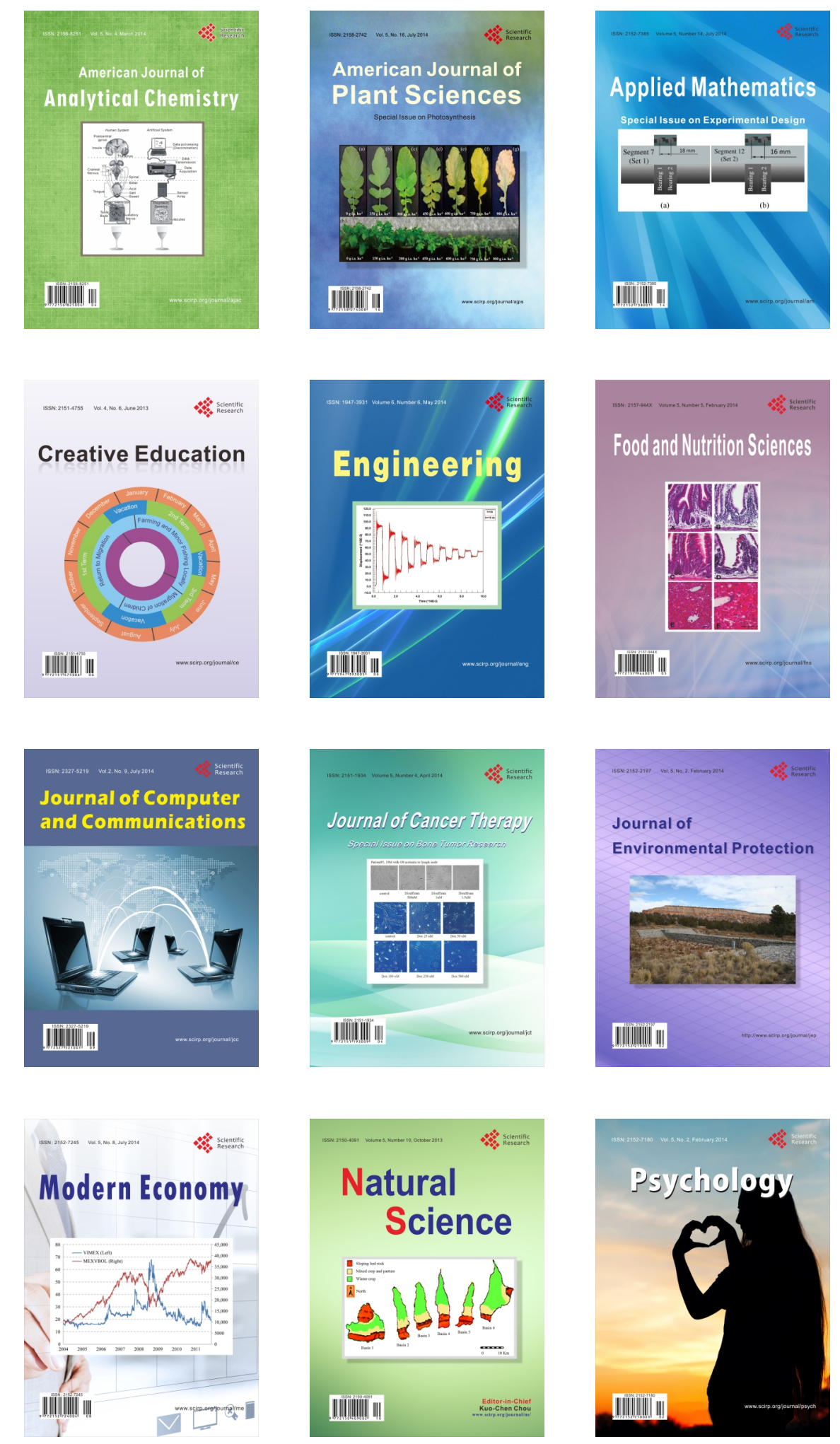